\title{
The Micro-Costing Approach to Foster the Effectiveness of Decision-Making Processes in the Healthcare System-Some Empirical Evidence from the Piedmont Region
}

\author{
Vania Tradori ${ }^{1}$, Paola De Bernardi ${ }^{1} \&$ Valerio Brescia ${ }^{1}$ \\ ${ }^{1}$ Department of Management, University of Turin, Italy \\ Corrispondence: Vania Tradori, Department of Management, University of Turin, C.so Unione Sovietica 218 bis, \\ Turin, Italy. E-mail: vania.tradori@unito.it
}

Received: November 19, 2018

Accepted: December 28, 2018

Online Published: January 27, 2019

doi:10.5539/ijbm.v14n2p167

URL: https://doi.org/10.5539/ijbm.v14n2p167

\begin{abstract}
The study aims to highlight the usefulness of micro accounting approach as tool of clinical governance starting from the data provided by the computerization of services and medical records. The case study takes into account data collected over two years between three departments of the same hospital for the management of patients with acute gastric ulcer with bleeding and variations and acute duodenal ulcer with bleeding and variations. All statistical analyses were performed using STATA V.14.2 (Stata Corp, College Station, Texas, USA, 2013) and p value $<0.05$ was considered significant for all analyses. The analysis of economic and comorbidity data provides useful insights to guide the choice of the treatment pathway between departments, and provides useful indications for the redefinition of guidelines towards a rationalization of healthcare expenditure.
\end{abstract}

Keywords: Micro-costing approach, health decision-making, Healthcare, performance management system, peptic ulcer bleending

\section{Introduction}

The growing attention to the financial balance of the Italian Healthcare System (IHS) has led, in recent years, to a reduction in the deficit and to an effective containment of the average annual growth rate of the overall health care per capita expenditure, which went from $1.7 \%$ in the period 2000-2010 to $0.7 \%$ per year between 2010 and 2016, among the lowest in the European Union (OASI, 2017). Specifically, a series of cost-containment measures which were implemented in the aftermath of the 2008 economic crisis, led to a reduction in public funding for health. Indeed, co-payments for medicines and for inappropriate use of hospital emergency services were implemented in most regions following the introduction of the Deficit Reduction Plans (EU Companion Report, 2017). According to the OASI report, public sources still cover $95 \%$ of hospital expenditure, but only $60 \%$ of expenditure on outpatient services and $65 \%$ of long-term care costs in residential facilities, which are defined as being the Achilles heel of the Italian Health System (OASI, 2017). While the IHS has been in economic equilibrium for some years, the report highlights: i) a gap between health resources and the needs of citizens/patients, characterised by a demographic aging, combined with the increase in life expectancy, which will further increase demand for care and ii) an alarming and permanent gap between the North and South of the country in terms of population health. In this background, the Italian healthcare spending, that is still much lower than that of other European countries, can only be reduced through the optimization of resources, organizational and technological innovation, citizen/patient empowerment and the definition of new skills for health professionals. The sustainability of the system over time, however, depends above all on the ways in which expenditure restraints have been obtained, making it necessary to analyse whether the focus of health policies and managerial choices has exclusively been, or mainly addressed to the linear reduction of individual consumption health system inputs (personnel costs, purchase of goods and services) or whether the focus was on the search for efficiency and effectiveness, encouraging optimal use of inputs in relation to outputs and outcomes of health services provided (Ballantine et al., 1998; Hill, 2000; Vannucci et al., 2001; Cinquini et al., 2007; Nuti et al., 2011; Tieghi et al., 2016; Murante et al., 2017). As a matter of fact, if overall the INH service is financially balanced, this does not necessarily correspond to the ability to respond to the needs of citizens and to provide services in an efficient and appropriate manner. Healthcare decisions to improve quality of patients' care require having good knowledge of the health condition (professional evidence), taking into account patient-specific 
aspects of medical care (contextual care), and contriving policy strategies to guarantee equity and appropriate use of resources, including avoiding waste (policy evidence) (De Maeseneer, 2017).

The research is inspired by the need of healthcare entities to rationalize the resources available (Leotta and Ruggeri, 2012), giving health professionals awareness of the costs related to alternative choices of intervention and treatment of the same pathology (Russo, 2011; Nuti et al., 2010), engaging them to optimize the choices and to improve the organizational and operational processes that lead to the expected outcomes (Smaldone and Vainieri, 2016). Many previous studies have already analyzed in depth the cost accounting systems in alternative care pathways, through the use of activity based and micro-costing approaches (Chan \& Ching, 1993; Evans et al., 1997; Ross, 2004; Pizzini, 2006; Cinquini et al., 2007; Russo, 2011; Goldberg and Kosinski, 2011, Battaglia and Pedretti, 2012; Perazzo et al., 2017; Rejeb et al., 2017). The present study is part of this line, assuming a costing perspective aimed at providing information for the choices and assessments addressed to the hospital management, in particular, focusing on the correlation between organizational aspects and the analysis of the specific resources consumed in each alternative. In practice, the analysis is conducted in depth on each individual patient, through the close collaboration between medical researchers and business professionals, whose goal and final intent is to verify the appropriateness of the resources used in relation to the treatment pathways and the outputs and outcomes obtained.

The research deals with the analysis of the efficiency of the therapeutic pathway carried out by the patients diagnosed with bleeding peptic ulcer at the main Piedmontese hospital "Città della Salute e della Scienza di Torino". The objective of the study is to assess and analyse the costs of the therapeutic process performed on each patient, according to the type of hospital ward (gastroenterology, general medicine and emergency medicine), in order to: i) determine the cost of each patient, based on the specific therapeutic path realized; ii) comparing the cost of alternative therapeutic pathways, based on the observational approach applied in agreement with the physicians, with the aim of hypothesising optimal intervention processes and optimization of the relative cost-benefit. Moreover, the study aims to determine if there is a statistical correlation between the variables that characterise the single cases being analysed (e.g. comorbidity, level of bleeding, method of treatment) that would allow the identification of significant variations in average length of stay and hospital costs, depending on the hospital ward where the patient is admitted.

The remainder of the study is structured as follows. In paragraph 2, a brief description of the literature makes it possible to understand the relevance and the dimensions analyzed. The paragraph 3 is dedicated to the research design, with a description of the methods of data collection and analysis, while in paragraph 4 the results of the analysis carried out in a Piedmontese hospital are presented and discussed. Paragraph 5 is dedicated to final conclusions and further research development.

\section{Literature Review}

In order to understand the implications related to both the objectives of the paper, the background analysis is as follow: a brief description of the pathology under study (2.1), the previous research related to "the managerialization" of the healthcare system (2.2) and the cost accounting approach applied in the case study (2.3).

\subsection{A Brief Description of the Peptic Ulcer Bleending}

Peptic ulcer bleeding is a disease of considerable interest from, undoubtedly, a medical point of view, as well as from an economic and management perspective. Indeed, it is one of the most important reasons why patients turn to a gastroenterologist, as well as being one of the most frequent diseases that requires hospital admission (Lin et al.; 1996; Gralnek et al, 2008). Peptic ulcer bleeding is the main cause of upper gastro-intestinal bleeding (UGIB), a condition which involves between 40 and 50 cases on average per 100,000 inhabitants annually and an estimated mortality risk estimated at around $8 \%$ of patients with the disease. In patients affected by UGIB from a non-variceal source around $80-90 \%$ are diagnosed, on the one hand, with duodenal peptic ulcer which develops in the upper part of the small intestine (15-35\% of cases) and, on the other, with gastric peptic ulcer which affects the stomach (10-25\% of cases) (Hreinsson et al., 2013a; Hreinsson et al., 2013b). It must be pointed out that there may be other causes responsible for UGIB, less common, but not less significant, although they are not mentioned here as they are not part of the present study. In light of these characteristics, it is clear that the treatment of the disease has a considerable impact on the number of emergency hospital admissions and, as a consequence, a high consumption of medical-healthcare and financial resources (Cheung \& Lau, 2009; Khamaysi \& Gralnek, 2013; Cassieri et al., 2016). In medical and economic literature, both national and international, fact-finding surveys aimed at demonstrating if there are significant differences in the various specialised treatments and care processes for the management of the ulcer and its complications are rare and not 
sufficiently detailed nor thorough. The most relevant studies are those of Quirk et al. (1997) carried out at the Harvard Medical School of Boston and of Pardo et al. (2002) carried out at the University Hospital of the Canary Islands in Tenerife. The analysis of Quirk et al. (1997) was conducted to ascertain if the cost of treating patients with upper gastro-intestinal bleeding varied on the basis of which hospital specialist care unit the patients were admitted to. Pardo et al. (2002) analysed the impact of physician specialty on the costs related to the treatment of non-variceal upper gastro-intestinal bleeding. Their studies clearly showed significant differences in response time to patient care in the various hospital wards and showed variations in the cost of treating patients in the different specialist care units (hospital department), while there were no differences related to risk factors. In particular, Pardo's et al. study identified a positive correlation between the implementation of specific evidence-based protocols by gastroenterologists and the reduction in the length of hospital stay and related costs. Following this theoretical introduction to the present study, the aim that arises is to analyse the methods of treating upper gastro-intestinal bleeding, measuring the economic effects in terms of the costs, through a study carried out at the Città della Salute e della Scienza di Torino during the period 2015-2016. The reference sample is made up of those patients managed by the Hospital who at the time of their discharge were found to have been diagnosed with upper gastro-intestinal bleeding. This medical centre is the biggest at a national and European level, with 9,500 employees, 2,311 beds and 181,330 emergency admissions in 2016 (Archives "Discharges and Services" - CSI Piedmont, 2016).

\subsection{The Current Relevance of the "Managerialization" of the Healthcare System}

In Italy, the healthcare sector represents one of the most important elements in the economic system with reference to: number of employees, variety of services on offer, consumption of resources, impact on growth and complexity of production methods. In the public healthcare service, the "managerialization" (Pollit, 1990; Newman and Clarke, 1994) of the National Healthcare System (NHS), which started with the Reforms of 1992-93 and reinforced with Legislative Decree 229/99, has progressively made the introduction of a well-structured and multifaceted system to assess healthcare qualitative and quantitative performances (Nuti et al., 2010; Del Gesso, 2014; Brescia et al. 2016; Nuti et al., 2016; Vaineri et al., 2017) and it is closely linked to the need to guarantee accountability in the public sector as well. Clinical Governance has been one of the management tools adopted in healthcare companies to pursue a continuous and progressive improvement in healthcare quality (Flynn, 2002; Swage, 2004; Scally \& Donaldson, 1998; Whitehead, 1991; WHO 1983). It gives two macro responsibilities to healthcare organisations: to continuously improve the quality of their services and to maintain high standards of care as well as high patient satisfaction (De Masi al., 2001; Nuti et al., 2017). The long-term goal of its implementation is to create an environment which stimulates the best professional performance (Quintaliani \& Gori, 2002). In more concrete terms, the fulfillment of Clinical Governance involves the full recognition of multidimensional performance indicators, which can be grouped into risk-controlled medical assistance, results-based efficiency, appropriate professional and organisational quality, patient-centredness approach to the planning and delivery of services (Pelissero, 2012) allowing for more accessible care and guaranteeing technical and allocative efficiency in the organisational system and in healthcare delivery (Fontana, 2005). Today it can be said that, in managerial terms, the level of maturity of healthcare entities has improved, with the formal affirmation of planning and control mechanisms, of managerial accounting tools and well-structured responsibility maps. However, despite this promising situation, the planning and control systems are often based on compliance with the requirements and procedures, rather than on the substantial need to lead the management towards multi-dimensional perspectives that include the expectations of all the stakeholders, putting at the center first and foremost the health objectives of the citizen, but also the healthcare professionals and staff who must be supported with appropriate motivational tools, coordination and identification of care priorities (Nuti et al., 2010; Murante et al., 2014; Vainieri et al, 2017). It is noticed (Vainieri et al., 2017) that healthcare entities should present a "reverse hierarchy" (or inverted pyramid) in which professionals take action on the delivery of quality and appropriate care whereas top management facilitates and orients their decisions and actions, supporting them with effective information strategies aimed to create value across the organization (Porter, 2010). In this context, the cost accounting approaches and specifically the micro-costing can lead to better decision-making processes.

\subsection{Micro-Cost Accounting Approach in Healthcare System}

The need of healthcare entities to rationalize the resources available and to give health professionals and managers the awareness of the costs related to organizational paths and alternative choices of intervention and treatments of patient diseases (Russo, 2011; Nuti et al., 2010) has boosted up researches on health cost accounting approaches. Many previous studies have already analyzed in depth the cost accounting systems in alternative care pathways, through the use of activity based and micro-costing methods (Chan and Ching, 1993; 
Evans et al., 1997; Ross, 2004; Pizzini, 2006; Cinquini et al., 2007; Russo, 2011; Goldberg and Kosinski, 2011, Battaglia and Pedretti, 2012; Perazzo et al., 2017; Rejeb et al. 2017). The design of a micro-costing approach is related to the cost estimation of the health service for promoting organizational behaviors consistent with the production of the service and with the appropriate use of resources (Heerey et al., 2002; Tarricone, 2004, Frick, 2009, Xu et al., 2014). The micro-costing method identifies different activities that the health entity performs, including the corresponding indirect costs (e.g. administrative and general costs) to estimate total cost of a procedure/organizational process (Cinquini et al., 2007). ABC method recognizes the relationship between costs, activities (called cost drivers) and products (e.g. exams, medical visit, intervention, ect) taking into account this relationship in the costing analysis (Frick, 2009). The adopted approach allows to recover the function of cost accounting system as a real support to decision-making processes through the enhancement of the link between cost information and management operations. The system improves the effectiveness in monitoring the processes of allocation and use of resources by which it's possible to pursue simultaneously the clinical and economic needs (Schreyogg, 2008; Tan et al., 2008; Smith et al., 2010; Rejeb et al., 2017). As pointed out by Vainieri et al. (2017) better managerial practices like planning, organizing, coordinating, controlling, and also instruments like cost accounting, are significantly related to better clinical and financial performance (Bloom et al., 2009).

As it has already mentioned before, the study is aimed, first of all, at verifying a possible correlation between the types of hospital ward (gastroenterology, general medicine and emergency medicine) and the determination of costs (fixed or variable) that generally result from the length of hospital stay, as well as clearly showing the causes of possible discrepancies. Secondly, the research pointed to determine if there is a statistical correlation between the variables that characterise the cases being analysed (e.g. comorbidity, level of bleeding, method of treatment) that would allow the identification of significant variations in average length of stay and hospital costs, depending on the hospital ward where the patient is admitted. Finally, the analysis of the results intends to evaluate how appropriate and "patient centred" is the level of organisation and allocation of the therapeutic and assistance processes.

\section{Research Design and Methods}

Using a shared protocol, the professionals and a team of researchers extracted and analyzed anonymous data from both regional and local databases including information on diagnosis and surgical procedures delivered to patients with peptic ulcer bleeding during the hospital stay. The data sources were: (i) the HDR database, which routinely collects data on hospital discharges, including referral source, discharge status, up to five discharge diagnoses (ICD- 9-CM), up to five hospital procedures (ICD-9-CM) and patient's demographic data; (ii) the surgical registry (SR) database, which includes a description of the interventions, the date and the time of the interventions. The ICD-9-CM (International Classification of Diseases - Ninth Revision - Clinical Modification) was used to define the patient sample (Deyo et al., 1992; Quan et al., 2005; Ministero della Salute, 2016).

The study sample consists of patients diagnosed with upper gastrointestinal bleeding - gastric or duodenal - who were hospitalised in the period 2015-2016 at the Molinette Hospital of the Azienda Ospedaliera Città della Salute e della Scienza di Torino. The discharged patients has been classified according to the type of their disease. Medical records of discharged patients with the above-mentioned disease were the main source of the data collected, analysed and re-elaborated for this research.

The departments involved for this study are the following: Gastroenterology (S.C. Gastroenterologia U), General Medicine (S.C. Medicina Interna 1 U, S.C. Medicina Interna 2 U, S.C. Medicina Interna 3 U, S.C. Medicina Interna 4 U, S.C. Medicina Interna 5, S.C. Medicina Interna 6), Emergency Medicine (S.C. Medicina Urgenza, MECAU) and Liver Failure and Liver Transplantation (SSD Insufficienza Epatica e Trapianto Epatico).

The ICD-9-CM coding system was applied to the Hospital Discharge Records (HDR) to subdivide the departments analysed, through the Quani programme (Ufficio Statistiche della S.C. Direzione Sanitaria). This originated 112 results. With the agreement of the Health Department, it was possible to analyse the medical records of 2015-2016 by inserting the identification code of each HDR/SDO into GesArcCC, the digital storage programme for medical records.

From the resulting sample $(\mathrm{n}=112), 22$ patients were excluded for the following reasons:

- $\quad$ patients without medical records in the GesArcCC system $(n=12)$;

- $\quad$ patients hospitalised in the Liver Failure and Liver Transplantation Departments $(n=8)$, considered not relevant;

- $\quad$ patients who voluntarily discharged themselves from the department $(\mathrm{n}=1)$;

- $\quad$ patients with perforated peptic ulcer $(n=1)$. 
Table 1. Sample patients per department

\begin{tabular}{llll}
\hline & $\mathbf{2 0 1 5}$ & $\mathbf{2 0 1 6}$ & Total \\
\hline Gastroenterology & 21 & 20 & $\mathbf{4 1}$ \\
General Medicine & 15 & 14 & $\mathbf{2 9}$ \\
Emergency Medicine & 9 & 11 & $\mathbf{2 0}$ \\
Total & 45 & 45 & $\mathbf{9 0}$ \\
\hline
\end{tabular}

Source: author's elaboration.

Summing up, a sample of 90 patients ( $n=45$ for $2015 ; n=45$ for 2016) diagnosed with acute gastric or acute duodenal ulcer with bleeding were identified, divided into the hospital departments, as in Table 1.

In this study, bleeding caused by 1$)$ acute gastric ulcer $(\mathrm{n}=46)$ and by 2$)$ acute duodenal ulcer $(\mathrm{n}=44)$ were considered homogenous because the relationship between the diagnostic-therapeutic procedure and the surgical procedure was the same in the two groups. Medical records of patients with bleeding peptic ulcer obtained from GesArcCC showed two macro-categories of variables: i) demographic and clinical features of the patients (e.g. sex; age; smoker; alcohol intake; corticosteroids consumption in the 30 days prior to admission; oral anticoagulant; antiplatelet therapy; previous episodes of bleeding peptic ulcer; comorbidity; ect.); ii) identification of health resources utilised and related costs during hospitalisation (e.g. number of days of hospital stay; number of Esophagogastroduodenoscopy (EGD) carried out during hospital stay; early diagnosis of EGD; previous interventional endoscopic therapy; previous endoscopic biopsy for detecting Helicobacter Pylori or for histological tests; number of blood bags transfused; type and screen tests required for transfusions; diagnostic and blood-chemistry tests prescribed; oral and infusion therapy administered during hospital stay).

The cost analysis has been conducted using the micro-costing approach (Heerey et al., 2002; Tarricone, 2004, Frick, 2009, Xu et al., 2014), that is, based on each individual patient admitted. Previous studies (Schreyogg, 2008; Smith et al., 2010; Tan et al., 2008; Rejeb et al., 2017) have demonstrated how micro-costing is especially useful for evaluating various healthcare activities/services. These are characterised by a wide range of interventions, combined with randomness, ex-ante, through the use of specific organisational standards, of care processes decided by the various healthcare providers operating along the "chain of care". In particular, since micro-costing is a "bottom-up" approach to determining the cost of a healthcare activity or process, it is considered the most accurate method for measuring the cost of activities in healthcare services, seeing that all the items are identified and evaluated in the most detailed fashion, allowing for a generally objective analysis, especially if it is supported by health information technologies (HIT) that can gather multidimensional information on care processes in a "capillary" way (Bardhan \& Thouin, 2013). The chosen method is not adaptable in a unique way, but some phases used in this study and inspired by prior studies (Frick, 2009, Smith et al., 2010 e Rejeb et al., 2017) can be identified: i) formal description of the healthcare process and activity; ii) data collection; iii) application of a monetary value to resources utilised (costs and prices) and finally iv) determination of the total cost.

After the identification of every single phase, it has detected what the cost drivers as variable with an economic impact on the departments involved:

- Number of days of hospitalisation;

- EGD and the interventional procedures/biopsies carried out;

- Number of transfused blood bags and TS tests requested;

- Diagnostic and blood-chemistry tests prescribed;

- Oral and infusion therapy administered.

The data for the average cost of a day of hospitalisation were obtained from the analytical accounting system data (financial and managerial accounting systems) in order to have a more systematic perspective, broken up into each item, as reported in table 2. 
Table 2. Analytical hospitalisation costs (€/day)

\begin{tabular}{llll}
\hline & Gastroenterology & General Medicine & Emergency Medicine \\
\cline { 2 - 4 } Personnel/Staff & 347.55 & 181.02 & 620.32 \\
Healthcare products & 10.50 & 8.29 & 23.88 \\
Non-Healthcare products & 0.76 & 0.69 & 1.03 \\
Services & 4.04 & 3.14 & 29.46 \\
Amortisation & 0.07 & 0.21 & 16.04 \\
Portion of general costs & 173.28 & 83.60 & 145.34 \\
\hline Total & 536.4 & 276.95 & 836.07 \\
\hline
\end{tabular}

Source: author's elaboration.

The costs of EGD, transfusions, diagnostic and blood-chemistry tests were taken from the regional price list for services in force during the two-year period under analysis. The cost of the products used for interventional procedures (adrenaline, fibrin glue, hemoclips, etc.) to ensure hemostasis during EGDs, together with the cost of medicines administered either orally or through infusions, were obtained from the AMC system (accounting and control accounting system). Table 3 shows a summary of the macro-items of healthcare resources for the treated patients.

Table 3. Macro-items of analysed healthcare resources in $€_{\mathbf{s}}$ (2015 and 2016). Separators are in thousands

\begin{tabular}{|c|c|c|c|c|c|c|}
\hline & \multicolumn{2}{|c|}{ Gastroenterology } & \multicolumn{2}{|c|}{ General Medicine } & \multicolumn{2}{|c|}{ Emergency Medicine } \\
\hline & 2015 & 2016 & 2015 & 2016 & 2015 & 2016 \\
\hline OGDS & $1,535.2$ & $1,984.7$ & $1,584.8$ & $1,560.3$ & 794.7 & $1,798,2$ \\
\hline Blood transfused & $1,329.9$ & $1,089.0$ & 522.9 & 574.5 & 687.0 & 411.9 \\
\hline Diagnostic procedures & $1,586.8$ & $2,064.1$ & $2,082.7$ & $3,491.1$ & $3,634.6$ & 622.4 \\
\hline Blood-chemistry & $4,209.5$ & $3,120.0$ & $3,160.7$ & $3,306.2$ & $2,148.2$ & $2,467.1$ \\
\hline Oral therapy & 273.7 & 156.9 & 111.8 & 296.6 & 111.3 & 136.1 \\
\hline Infusion therapy & 409.2 & 291.6 & 1203.7 & 228.5 & 199.6 & 198.6 \\
\hline Total & $9,344.3$ & $8,706.3$ & $8,666.6$ & $9,457.2$ & $7,575.4$ & $5,634.3$ \\
\hline
\end{tabular}

Source: author's elaboration.

To describe the overall health of patients and to remove non-peptic ulcer related distorting factors from the study, the comorbidities found at the time of admission to the ward were considered. The Charlson Comorbidity Index (CHI), an indicator expressing the probability of survival in patients with multiple concomitant pathologies (Charlson, 1987, 1994) was calculated using these comorbidities for each patient in a readapted and validated version (Librero et al., 1999). Compared to the original version, rheumatic diseases and the acquired immune deficiency syndrome (AIDS) were included, which had not previously been considered by Charlson. An individual's comorbidity score is based on the parameters measured by an episode and the scores that correspond to the measured parameters between episodes of an individual in the following way: chronic disease codes are evaluated in the corresponding episode only when they have been classified as a secondary diagnosis but are not the primary diagnosis. Acute disease codes are not counted in the episode in which they are recorded. Both types of codes are accumulated for each patient and counted in the comorbidity index of subsequent episodes (the first admission available at the hospital is used as an index episode, and no previous admission comorbidity has been added). Only one disease is counted in each of the groups (for example, a patient with cerebrovascular disease and neoplasms has a weight of $1+2=3$, but a patient with two neoplasms has a weight of 2 and not $2+2$ ). The weight of the original comorbidity index has been maintained for the different categories together with the calculation of the total score, which is reached by adding the weights of the different categories. Subsequently, from a more limited perspective compared to the disease treated, the Forrest classification (1974) was used, with the aimed at standardising, as much as possible, the type of bleeding peptic ulcers, stratifying the patients into high, intermediate and low risk of bleeding. This was done in order to verify whether the medical procedures that were performed and the related costs were consistent with the guidelines provided for each degree of severity of the peptic ulcer. 


\section{Results and Descriptive Analysis}

The main objective of the study, which gives rise to important considerations, is to determine whether the hospital department the patient with a bleeding peptic ulcer is allocated to makes it possible to predict the length of the stay and the total costs incurred, in the light of potential distorting factors which are not strictly related to the disease. The characteristics of the sample on which the statistical studies were carried out are summarised in table 4 .

Table 4. Characteristics of the sample - all the data is expressed as a numerical value, percentage and/or mean \pm standard deviation

\begin{tabular}{lllll}
\hline Characteristics & Gastroenterology & General Medicine & Emergency Medicine & p-value \\
\hline Number & 41 & 29 & 20 & 0.257 \\
Average age & $61 \pm 16.81$ & $72 \pm 18.59$ & $70 \pm 16.07$ & 0.841 \\
Gender & & & & \\
Male & $30(73.2 \%)$ & $17(58.6 \%)$ & $4(80 \%)$ & 0.059 \\
Female & $11(26.8 \%)$ & $12(41.4 \%)$ & $4(20 \%)$ & \\
Smokers & & & & 0.176 \\
Not asked & $15(36.6 \%)$ & $17(58.6 \%)$ & $5(25 \%)$ & \\
Yes & $15(36.6 \%)$ & $8(27.6 \%)$ & $2(10 \%)$ & \\
No & $11(26.8 \%)$ & $4(13.8 \%)$ & & 0.923 \\
Alcohol & & & $3(15 \%)$ & 0.115 \\
Not asked & $23(56.1 \%)$ & $24(82.8 \%)$ & $2(10 \%)$ & 0.733 \\
Yes & $10(24.4 \%)$ & $3(10.3 \%)$ & $2(10 \%)$ & 0.902 \\
No & $8(19.5 \%)$ & $2(6.9 \%)$ & $10(50 \%)$ & $8(40 \%)$ \\
Corticosteroids & $5(12.9 \%)$ & $7(24.1 \%)$ & $9 \pm 3.70$ & \\
Oral anti-coagulant therapy & $13(31.7 \%)$ & $15(51.7 \%)$ & $7,649.4 \pm 3,095.81$ & \\
Pre-existing peptic haemorrhage & $14(34.1 \%)$ & $9(31 \%)$ & $8,354.78 \pm 3,635.31$ & \\
Average days of stay & $9 \pm 4.83$ & $14 \pm 9.71$ & $3,858.90 \pm 2,689,62$ & \\
Average cost of stay & $4,941.66 \pm 2,591.47$ & $4,506.76 \pm 3,336,06$ & & \\
Total average cost & $5,406.76 \pm 2,733.38$ & & & \\
\hline
\end{tabular}

Source: author's elaboration.

The clinical variables reported were the subject of the ANOVA tests, which were carried out using the Stata 14.2 software (Stata Corp., College Station, Texas, USA, 2013). Each result shows a p-value higher than 0.05 allows the comparability of the observed groups. Leaving aside the analysis of medical conditions and clinical results with reference to patients, it is essential to focus on the variables which are directly attributable to cost sources, examining the reasons for the inconsistencies found. The average number of days of hospitalisation is higher in the General Medicine department (14 days \pm 9.7 DS), compared to the Gastroenterology department ( 9 days \pm 4.8 DS) and the Emergency Medicine department (9 days \pm 3.7 DS). Nevertheless, the average cost recorded for the stay in General Medicine is the lowest ( $€ 3,858 \pm 2,690$ DS), increases for the Gastroenterology department $(€ 4,941 \pm 2,591$ DS) and rises even further for the Emergency Medicine department ( $€ 7,649 \pm 3,096$ DS). This misalignment between the average period of hospitalisation and the average cost of hospitalisation is caused by the profound differences in the $€ /$ day cost attributed to each department, as already seen in the cost data in Table 2. The cost per day for hospitalisation in Gastroenterology is $€ 536$, in General Medicine it is $€ 277$ and in Emergency Medicine it is $€$ 836. It should be noted, however, that in the face of a considerable economic difference, there is a p-value calculated for total costs of 0.102 , i.e. statistically the distribution of costs among the various departments is considerably homogeneous. Consequently, the different average length of stay is the compensatory factor, which is higher in the least expensive department but lower in the others. Moreover, the cost of hospitalisation is undoubtedly the most significant component of the total cost of managing patients suffering from bleeding peptic ulcers, accounting for $85.6 \%$ of the total cost of General Medicine $(€ 3,858$ out of $€ 4,507), 91.4 \%$ of the total spent in Gastroenterology ( $€ 4,941$ out of $€ 5,407)$ and as high as $91.5 \%$ of the total in Emergency Medicine ( $€ 7,649$ out of $€ 8,354)$. A more detailed examination into the analytical breakdown of the hospitalisation costs shows that the item "personnel" accounts for the highest share: $65.3 \%$ in General Medicine, $64.8 \%$ in Gastroenterology and $74.2 \%$ in Emergency Medicine. As a fixed cost it is unchangeable, at least in the short-medium term. It is true that the size of the sample which was analysed is small compared to the 
data relating to the overall Italian healthcare expenditure. Finally, it is noted that there is no considerable statistical difference $(\mathrm{p}=0.757)$ between the three departments regarding the costs of managing bleeding peptic ulcers, i.e. including OGDS, interventional procedures/biopsies, transfused blood bags, blood transfusion required, prescribed diagnostic and blood-chemistry tests and the oral and infusive therapy provided. The main reason is attributable to the lack of a real diagnostic-therapeutic strategy which is specific for each department. Numerous and multivariate linear regressions were carried out on the entire sample, as well as on the individual departments, in order to have a statistical degree of correlation between the variables that characterise the cases being analysed and to establish whether the treatment of bleeding ulcers leads to variations in terms of the length of hospitalisation and total cost depending on which department the patients are sent to STATA V.14,2 was used to conduct all the studies, taking a $\mathrm{p}$ value $<0.05$ to be significant. The robustness of the analyses carried out was verified. First of all, it is noted that the increase in the patients' age corresponds to an increase in the number of days spent in hospital for the entire sample $(p=0.032$; R-Squared $=0.0834)$, and the robustness of the model is $8.34 \%$. This is interesting if the number of cases examined is taken into consideration.

The study continued with an assessment of the degree of correlation between comorbidity and hospitalisation costs and, subsequently, the one between the severity of the bleeding and the hospitalisation costs. The increase in the number of diseases present at the same time corresponds to an increase in the length of hospitalisation $(\mathrm{p}=$ 0.002 ; R-Squared $=0.103$ ). If it is applied to each department, this correlation remains for Gastroenterology $(\mathrm{p}=$ 0.047 ; R-Squared $=0.097)$ and for Emergency Medicine $(p=0.037$; R-Squared $=0.219)$, while General Medicine is the exception $(p=0.282 ; \mathrm{R}$-Squared $=0.046$ ). Despite not having the same economic impact as the length of hospitalisation, it is still worth noting that even the diagnostic-therapeutic costs grow in relation to increases in comorbidity $(\mathrm{p}=0.032$; R-Squared $=0.005)$. As can be expected, the linear regression of comorbidity-total costs is also significant $(\mathrm{p}=0.001$; R-Squared $=0.114)$. Returning more specifically to the limited level of the treated disease, a linear regression was carried out on the total number of cases being studied between the three risk groups defined by Forrest (high, intermediate and low risk), assigned to the patients at the time of the EGD, and the number of days of hospitalisation. The overall result deviates from what had previously been expected, as there is no statistically significant correlation $(\mathrm{p}=0.161)$. The increase in haemorrhagic severity does not correspond to a linear increase in the days spent on the ward. In order to interpret the reasons for this, regressions were also conducted into the situations of the individual hospitals. The only department to have reported an increase in the days of hospitalisation, proportionate to the risk defined by Forrest, was that of General Medicine $(p=0.035$; R-Squared $=0.167)$. There is no linear correlation between the length of stay and the severity of bleeding in the Gastroenterology department $(\mathrm{p}=0.262$; R-Squared $=0.032)$ and in the Emergency Medicine department $(p=0.766$; R-Squared $=0.005)$. In short, the type of bleeding has practically no impact on the length and cost of the three groups. This is supported by the fact that applying the same Forrest risk class there is no significant difference in the average number of days of hospitalisation, taking into account the relative costs differentiated for hospitalization: 6 days in Emergency Medicine, 7.1 days in Gastroenterology and 9.8 days in General Medicine. In other words, not detecting the severity of bleeding, together with to the fact that the panorama of clinical criticality is age-related, it is clear that the variable that most affects the cost of medical treatment is the level of comorbidity.

Table 5. Breakdown by levels of comorbidity.

\begin{tabular}{lllll}
\hline Comorbidity & Gastroenterology & General Medicine & $\begin{array}{l}\text { Emergency } \\
\text { Medicine }\end{array}$ & Breakdown \% (n) per levels of comorbidity \\
\hline $\mathbf{0}$ & $15(36.6 \%)$ & $5(17.2 \%)$ & $4(20 \%)$ & $\mathbf{2 6 . 6 \%}(\mathbf{n}=\mathbf{2 4})$ \\
$\mathbf{1}-\mathbf{2}$ & $18(43.9 \%)$ & $12(41.4 \%)$ & $9(45 \%)$ & $\mathbf{4 3 . 3 \%}(\mathbf{n}=\mathbf{3 9})$ \\
$\geq \mathbf{3}$ & $8(19.5 \%)$ & $12(41.4 \%)$ & $7(35 \%)$ & $\mathbf{3 0 . 1} \%(\mathbf{n}=\mathbf{2 7})$ \\
\hline
\end{tabular}

Source: author's elaboration.

On the basis of the above, an analysis of the data in Table 5 risks leading to the conclusion that the economically logical allocation of the therapeutic-assistance process should be made by levels of comorbidity, that is, to allocate to the most onerous wards the patients with none or few comorbidities, since the likelihood that they will stay in a less severe department is high. This statement is incorrect for at least two reasons:

from an economic-statistical point of view, the significant correlation between the level of comorbidity and the extent of hospitalisation is verified only retrospectively, i.e. with the specific departmental allocations made in the two-year period under analysis; 
- $\quad$ patients with numerous pathologies treated in a non-specialised ward would generate a lengthening of the stay, thus eliminating any economic advantage.

Furthermore, from a clinical point of view, as has been previously on several occasions, in addition to the efficiency required in the allocation of the resources, it is also necessary to take into consideration therapeutic effectiveness, professional appropriateness and the results of the process.

\section{Conclusions and Further Research Development}

Compared to the analysis carried out by Quirk et al. (1997) and Pardo et al. (2002), during this study the definition of costs was made in analytic terms on each individual patient so as to make it possible to define the micro-costing average of each cost taken into consideration in the best possible way. Both the Pardo et al. (2002) study and ours also take into consideration the costs of the diagnosis. The analysis shows results which are consistent with findings from previous studies, thus it is possible to make a generalisation regarding all the health authorities whose organisation and the allocation of patients are carried out in the same way. In this scenario, the implementation of strategies aimed at effectively containing hospital health costs, thus reducing the length of time stable patients remain in hospital, becomes a decisive factor (Saiani \& Brugnolli, 2014). Even though there is also a fairly wide range of potential corrective measures available, there are three main areas (Gabrielli et al., 2007). First of all, it is essential to reduce the length of stay in hospital, maintaining the quantity and quality of the diagnostic-therapeutic procedures, by means of a variety of joint efforts:

- The use of hours of the day that have been considered previously to carry out the diagnostic procedures, such as the evenings or holidays;

- The gradual replacement of the step-by-step method with the immediate request for potentially useful assessments;

- Accurate detection, prior to admittance to the hospital ward, of the seriousness of the case in order to send the patients to the suitable department;

- Reduction of cases where, due to the lack of clear and strict guidelines, doctors are resorted to basing the clinical picture solely on their experience.

Secondly, the high number of procedures, which often turn out to be superfluous, which are implemented to make a diagnosis, has a huge impact on the total costs. The elimination of some routine tests which are not specific or, in some circumstances, are simply aimed at avoiding liability, known as defensive medicine (Roiati, 2012). Finally, the last factor which has been the subject of lengthy discussion, is that of analytical conformity which establishes the daily cost for a hospital stay. It is currently deemed to be a variable which cannot be modified, as it is composed of fixed costs. However, long-lasting results may be obtained by re-configuring the organisational processes, limiting waste and organically assessing the key performances which have already been discussed in depth. A prolonged hospital stay is neither economically viable nor positive for the health of the patient. In fact, there are frequent cases of extremely long waiting times for a hospital bed, thus increasing the risk of infection and cognitive impairment, especially in elderly patients. It is precisely for all these reasons that it is essential to avoid the procedures for the discharge from hospital which are clinically and / or socially complex, delayed or early discharges or those that have not been sufficiently prepared, as the latter can lead to numerous cases where the patient is then re-admitted into hospital or has to return several times. The hope is that in future organisation will be based on the intensity of the treatment in order to distribute the personnel costs in a homogeneous way on the basis of the levels of comorbidity or gravity (Nicosia \& Lagostena, 2008; Gualano et al., 2016). However, as previous studies has highlighted (Smaldone and Vainieri, 2016; Nuti et al., 2017; Murante et al., 2017), it is not sufficient to put in place performance measurement systems and tools, these should be disclosed with effective communication strategies throughout the whole organization fostering the cognitive effect of performance measurement and giving feedback information to support the decision-making processes both of physicians and management professionals. Further research could be performed with the aim to consider the adoption of multi-level and multi-dimensional evidence based performance measurement systems, strictly correlated with soft management styles able to promote the sharing of knowledge and leverage learning processes to promote organizational and management innovation. Finally, an appropriate understanding and interpretation of the economic performance data often requires additional qualitative data collection more patient-centred, for example, indicators able to shed light on patients' expectations, experiences and health behaviour. 


\section{References}

Ballantine, J., Brignall, S., \& Modell, S. (1998). Performance Measurement and Management in Public Health Services: A comparison of UK and Swedish Practice. Management Account Research, 9(1), 71-94. https://doi.org/10.1006/mare.1997.0067

Bardhan, I. R., \& Thouin, M. F. (2013). Health information technology and its impact on the quality and cost of healthcare delivery. Decis Support Syst, 55(2), 438-449. https://doi.org/10.1016/j.dss.2012.10.003

Battaglia, G., \& Pedretti, F. (2012). ABC nella riabilitazione: la presa in carico in ciclo diurno continuo per l'età evolutiva. Mecosan, 81, 75-85.

Bloom, N., Propper, C., Seiler, S., \&Van Reener, J. (2009). Management practices in hospitals. Health, Econometrics and Data Group No.09/23.

Brescia, V., Rainero, C., Puddu, L., Gualano, M. R., \& Bert, F. (2016). La formazione come strumento di management nella sanità. Sviluppo \& Organizzazione, 56-67.

Cassieri, C., Crispino, P., Frualdo, M., Gnerre, P., Marzano, C., Mucci, L., Zanon, M., \& Zippi, M. (2016). Gestione del paziente con sanguinamento del tratto digestivo superiore di origine non varicosa: dall'evidenza alla pratica clinica. Articolo presente nei quaderni - Italian Journal of Medicine. Pavia.

Cergas-SDA, B. (2017). Osservatorio sulle aziende e sul sistema sanitario italiano. Rapporto OASI 2017, Milano: Egea.

Chan, Y., \& Ching, L. (1993). Improving hospital cost accounting with activity-based costing. Health Care Management Review, Winter, 18(1). https://doi.org/10.1097/00004010-199324000-00008

Charlson, M. E., Pompei, P., Ales, K. L., \& MacKenzie, C. R. (1987). A new method of classifying prognostic comorbidity in longitudinal studies: development and validation. Journal of Chronic Diseases, 40(5), 373-383. https://doi.org/10.1016/0021-9681(87)90171-8

Charlson, M., Szatrowski, T. P., Peterson, J., \& Gold, J. (1994). Validation of a combined comorbidity index. Journal of Clinical Epidemiology, 47(11), 1245-1251. https://doi.org/10.1016/0895-4356(94)90129-5

Cheung, F. K., \& Lau, J. Y. (2009). Management of massive peptic ulcer bleeding. Gastroenterology Clinics of North America, 38(2), 231-243. https://doi.org/10.1016/j.gtc.2009.03.003

Cinquini, L., Miolo, P., Pittalis, A., \& Campanale, C. (2007). Il costo dell'intervento chirurgico in laparoscopia mediante l'activity-based costing. Mecosan, 103-126.

CSI Piemonte. (2016). Dimessi e Prestazioni Ospedale della Salute e della Scienza di Torino, Archivio interno.

De Maeseneer, J., Gent, U., \& Boeckxstaens, P. (2017). Pay-for-performance : beter niet aan beginnen? Minerva, Nederlandse Ed. 16(4), 82-83.

De Masi, G., Plastino, V., \& Vitale, R. (2001). Progettare la qualità nelle residenze per anziani: strumenti di valutazione e verifica. (Vol. 117). Milano: FrancoAngeli.

Del Gesso, C. (2014). La visione sistemica dell'Azienda sanitaria pubblica. Tendenze evolutive dell'organizzazione, della gestione e della rilevazione nel sistema di tutela della salute. Milano: FrancoAngeli.

Deyo, R. A., Cherkin, D. C., \& Ciol, M. A. (1992). Adapting a clinical comorbidity index for use with ICD-9-CM administrative databases. Journal of Clinical Epidemiology, 45(6), 613-619. https://doi.org/10.1016/0895-4356(92)90133-8

European Commision. (2017). State of Health in the EU. https://ec.Europa.eu/health/sites.

Evans, J. H., Hwang, Y., \& Nagarajan, N. J. (1997). Cost reductionand process reengineering in hospitals. Journal of cost management, 11(3), 20-27. https://doi.org/10.1016/s0278-4254(00)00024-7

Flynn, R. (2002). Clinical governance and governmentality. Health, Risk \& Society, 4(2), 155-173. https://doi.org/10.1080/13698570220137042

Fontana, F. (2005). Clinical governance: una prospettiva organizzativa e gestionale (Vol. 23). Milano: FrancoAngeli.

Frick, D. 2009). Microcosting quantity data collection methods. Med Care., 47,S76-S81. https://doi.org/10.1097/mlr.0b013e31819bc064

Gabrielli, A., Pasquali, S., Pietracci, L., Pomponio, G., Pupita, G., Raggetti, G., \& Tirotta, D. (2007). Il ricovero 
diagnostico in Medicina Interna: efficacia clinica, impatto economico, criticità. Recenti progressi in Medicina, 98(10).

Goldberg, M. J., \& Kosinski, L. (2011). Activity-Based Costing and Management in a Hospital-Based GI Unit. Clinical Gastroenterology and Hepatology, 9(11). https://doi.org/10.1016/j.cgh.2011.08.010

Gralnek, I. M., Barkun, A. N., \& Bardou, M. (2008). Management of acute bleeding from a peptic ulcer. New England Journal of Medicine, 359(9), 928-937. https://doi.org/10.1056/nejmra0706113

Gualano, M. R., Lovato, E., Bert, F., Camussi, E., Capizzi, S., Poscia, A., Brescia, V., Anessi, P. E., Gianino, M. M., \& Siliquini, R. (2016). Planning, budgeting and control systems, and management strategies of inputs in lean hospitals: literature review and potentialities of HTA. International Journal Series in Multidisciplinary Research, 2(3), 51-62.

Heerey, A., McGowan, B., Ryan, M., \& Barry, M. (2002). Microcosting versus DRGs in the provision of cost estimates for use in pharmacoeconomic evaluation. Expert Rev Pharmacoecon Outcomes Res., 2, 29-33. https://doi.org/10.1586/14737167.2.1.29

Hill, N. T. (2000). Adoption of costing systems in US hospitals: An event history analysis 1980-1990. Journal of Accounting and Public Policy, 19, 41-71. https://doi.org/10.1016/s0278-4254(99)00013-7

Hreinsson, J. P., Gumundsson, S., Kalaitzakis, E., \& Björnsson, E. S. (2013a). Lower gastrointestinal bleeding: incidence, etiology, and outcomes in a population-based setting. Epean Journal of Gastroenterology \& Hepatology, 25(1), 37-43. https://doi.org/10.1097/meg.0b013e32835948e3

Hreinsson, J. P., Kalaitzakis, E., Gudmundsson, S., Björnsson, E. S. (2013b). Upper gastrointestinal bleeding: incidence, etiology and outcomes in a population-based setting. Scandinavian Journal of Gastroenterology, 48(4), 439-447. https://doi.org/10.3109/00365521.2012.763174

ISTAT. (2017). Il sistema dei conti della sanità per l'Italia. 4 Luglio 2017 World Health Organization. The principles of quality assurance. Copenaghen (Report on a WHO meeting).

Khamaysi, I., \& Gralnek, I. M. (2013). Acute upper gastrointestinal bleeding (UGIB) - initial evaluation and management. Best practice \& research Clinical Gastroenterology, 27(5), 633-638. https://doi.org/10.1016/j.bpg.2013.09.002

Leotta, A., \& Ruggeri, D. (2012). I cambiamenti nei sistemi di misurazione e valutazione manageriale nelle aziende ospedaliere universitarie come contesti multi-stakeholder: proposizioni teoriche ed evidenze empiriche. Management Control, 3, 63-86.

Librero J., Peiró S., \& Ordiñana R. (1999). Chronic comorbidity and outcomes of hospital care: length of stay, mortality, and readmission at 30 and 365 days. Journal of clinical epidemiology, 52(3), 171-179. https://doi.org/10.1016/s0895-4356(98)00160-7

Lin, H. J., Wang, K., Perng, C. L., Chua, R. T., Lee, F. Y., Lee, C. H., \& Lee, S. D. (1996). Early or delayed endoscopy for patients with peptic ulcer bleeding: a prospective randomized study. Journal of clinical Gastroenterology, 22(4), 267-271. https://doi.org/10.1097/00004836-199606000-00005

Mariani, L., Tieghi, M., \& Gigli, S. (2016). The efficacy of performance management system in healthcare. A literature review and research perspectives. Management Control, 3, 97-116. https://doi.org/10.3280/maco2016-003006

Ministero della Salute. (2016). La Scheda di Dimissione Ospedaliera (SDO). http://www.salute.gov.it/portale/temi/p2_6.jsp?id=1232\&area=ricoveriOspedalieri\&menu=vuot Consultato il 30/08/2016.

Ministero della Salute. (2016). La classificazione delle malattie ICD-9-CM. http://www.salute.gov.it/portale/temi/p2_5.jsp?area=ricoveriOspedalieri\&menu=classificazione Consultato il 30/08/2016.

Ministero della Salute. (2017). Italiane Health strategy implementation. Health Information Exchange, Mirage to reality, IHE-€pe Connectathon

Murante, A., Candelori, S., Rucci, P., Nuti, S., Roncella, M., Ghilli, M., Mercatelli, A., \& Fantini, M. P. (2017). Innovation through performance indicators. The case of the breast-conserving surgery indicator. BMC Res Notes, 10, 288.

Murante, A., Vainieri, M., Rojas, D., \& Nuti, S., (2014). Does feedback influence patient - professional 
communication? Empirical evidence from Italy. Health Policy, 116(2-3), 273-80.

Newman, J., \& Clarke, J. (1994). Going about our business. The managerialization of public services, John Clarke Allan Cochrane Eugene McLaughlin, Managing Social Policy. London: Sage Publications.

Nicosia, F., Tramalloni, R., \& Lagostena, A. (2008). Ospedale "lean" per intensità di cure. Management della sanità, 12, 36-40.

Nuti, S., Bini, B., Grillo, R. T., Piaggesi, A., \& Ricci, L. (2016). Bridging the gap between theory and practice in integrated care: the case of the diabetic foot pathway in Tuscany. Internationale Journal of Integrated Care, 16(2), 1-14. https://doi.org/10.5334/ijic.1991

Nuti, S., Calabrese, C., \& Panero, C., (2010). Il confronto tra i bisogni del paziente e offerta sanitaria per il miglioramento organizzativo del percorso oncologico. Milano, IT: Economia Sanitaria.

Nuti, S., Daraio, C., Speroni, C., Vainieri, M. (2011). Relationship between technical efficiency and the quality and costs of health care in Italy. International Journal for Qualitiy in Health Care, 23(3), 324-330. https://doi.org/10.1093/intqhe/mzr005

Nuti, S., De Rosis, S., Bonciani, M., \& Murante, A. M. (2017). Rethinking Healthcare Performance Evaluation Systems towards the People- Centredness Approach: Their Pathways, their Experience, their Evaluation. Healthcare papers, 56-64. https://doi.org/10.12927/hcpap.2017.25408

Pardo, A., Durández, R., Hernández, M., Pizarro, A., Hombrados, M., Jiménez, A., Planas, R., \& Quintero, E. (2002). Impact of physician specialty on the cost of nonvariceal upper GI bleeding care. The American journal of gastroenterology, 97(6), 1535-1542. https://doi.org/10.1111/j.1572-0241.2002.05695.x

Pellissero, G. (2012). Ospedali \& Salute. Decimo rapporto annuale 2012, Ermeneia - Studi \& Strategie di Sistema, Milano, FrancoAngeli, 69-71.

Perazzo, J., Reyes, D., \& Webel, A. (2017). A systematic review of health literacy interventions for people living with HIV. AIDS and Behavior, 1(3), 812-821. https://doi.org/10.1007/s10461-016-1329-6

Pizzini, M. (2006). The relation between cost system design, managers evaluation of the relevance and usefulness of cost data and finanzial performance: an empirical study of US hospitals. Accounting, Organizations and Society, 31, 179-210. https://doi.org/10.1016/j.aos.2004.11.001

Pollitt, C. (1990). Managerialism and the Public services. Oxford. Basil Blackwell.

Porter, M. E. (2010), What Is Value in Health Care? The New England Journal of Medicine, 363, 2477-2481. https://doi.org/10.1056/nejmp1011024

Quan, H., Sundararajan, V., Halfon, P., Fong, A., Burnand, B., Luthi, J. C., Saunders, L.D., Beck, C. A., Deasby, T. E., \& Ghali, W. A. (2005). Coding algorithms for defining comorbidities in ICD-9-CM and ICD-10 administrative data. Medical care, 1130-1139. https://doi.org/10.1097/01.mlr.0000182534.19832.83

Quintaliani, G., \& Gori, F. (2002). I sistemi di Qualità e l'Appropriatezza Professionale. Azienda Ospedaliera Perugia.

Quirk, D. M., Barry, M. J., Aserkoff, B., \& Podolsky, D. K. (1997). Physician specialty and variations in the cost of treating patients with acute upper gastrointestinal bleeding. Gastroenterology, 113(5), 1443-1448. https://doi.org/10.1053/gast.1997.v113.pm9352845

Rejeb, O., Pilet, C., Hamana, S., Xie, X., Durand, T., Aloui, S., Doly, A., Biron, P., Perrier, L., \& Augusto, V. (2017). Performance and cost evaluation of health information systems using micro-costing and discrete-event simulation. Health Care Manag Sci. https://doi.org/10.1007/s10729-017-9402-x

Roiati, A. (2012). Medicina difensiva e colpa professionale medica in diritto penale. Tra teoria e prassi giurisprudenziale. Roma: Giuffrè Editore.

Ross, T. K. (2004). Analyzing Health Care Operations Using ABC. Journal of Health Care Finance, 30(3), 1-20.

Russo, S. (2011). L'ABC e il benchmarking di processo nella valutazione delle attività di day surgery. Mecosan, 80 .

Saiani, L., \& Brugnolli, A. (2014). Trattato di cure infermieristiche. Napoli: Casa Editrice Idelson-Gnocchi.

Scally, G., \& Donaldson, L. J. (1998). Clinical governance and the drive for quality improvement in the new NHS in England. Bmj, 317(7150), 61-65.

Schreyogg, J. (2008). A micro-costing approach to estimating hospital costs for appendectomy in a cross-€pean 
context. Health Econ, 17(1), 59-69. https://doi.org/10.1002/hec.1323

Smaldone, P., \& Vainieri, M. (2016). Motivating health professionals through control mechanisms: A review of empirical evidence. Journal of Hospital Administration, 5, 67-75. https://doi.org/10.5430/jha.v5n3p67

Smith, M. W., Barnett, P. G., Phibbs C. S., \& Wagner T. H. (2010). Microcost methods for determining VA healthcare costs, guidebook. Health Economics Resource Center, HERC.

Swage, T. (2004). Clinical governance in health care practice. Elsevier Health Sciences.

Tan, S. S., Van, R. L. H., Al, M. J., Bouwmans, C. A., Hoogendoorn, M. E., Spronk, P. E., \& Bakker, J. (2008). A microcosting study of intensive care unit stay in the Netherlands. J Intensive Care Med, 23(4), 250-257. https://doi.org/10.1177/0885066608318661

Tarricone, R. (2004). Valutazioni economiche e management in sanità. Milano: McGraw-Hill.

Vainieri, M., Ferrè, F., Giacomelli, G., \& Nuti, S. (2017). Explaining performance in health care: How and when top management competencies make the difference. Health Care Management Review. https://doi.org/10.1097/hmr.0000000000000164

Vannucci, A., Abati, R., Bozza A. G., Mattiolo, G., \& Villani, G. (2001). L'analisi dei costi per processo: un metodo per migliorare la qualità delle prestazioni e la loro efficienza operativa. Esperienza applicativa in un servizio per le tossicodipendenze. Bollettino delle Farmacodipendenze e Alcolismo, 24(3), 26-33.

Whitehead, M. (1991). The concepts and principles of equity and health. Health Promotion International, 6(3), 217-228. https://doi.org/10.1093/heapro/6.3.217

Xu, X., Lazar, C., Grossetta Nardini, H. K., \& Ruger, J. P. (2014) Micro-costing studies in the health and medical literature: a systematic review. Systematic Reviews, 3, 47. https://doi.org/10.1186/2046-4053-3-47

\section{Copyrights}

Copyright for this article is retained by the author(s), with first publication rights granted to the journal.

This is an open-access article distributed under the terms and conditions of the Creative Commons Attribution license (http://creativecommons.org/licenses/by/4.0/). 